\title{
Community wide analysis of IBD in Rochester, New York, January 1973 to December 1989: Epidemiologic description with detailed clinical analysis
}

\author{
STEPHEN P STOWE, MD, JAMES M STORMONT, MD, ASHOK N SHAH, MD,
}

LAWRENCE N CHESSIN, MD, HARRY L SEGAL, MD, WILLIAM Y CHEY, MD

SP STOWE, JM STORMONT, AN SHAH, LN CHESSIN, HL SEGAL, WY CHEY. Community wide analysis of IBD in Rochester, NewYork, January 1973 to December 1989: Epidemiologic description with detailed clinical analysis. Can J Gastroenterol 1993;7(2):149-154. Inflammatory bowel disease (IBD) is a moving target with regional variations as to incidence and prevalence of Crohn's disease and ulcerative colitis, and a wide variation in rates of IBD as per year of description. Community wide population studies conducted over a period of many years can best detail trends in IBD and its complications, and the impact of medical and surgical therapy. The Colitis Ileitis Study Group of Rochester, New York, established a hospital-based community wide cumulative registry of Crohn's disease and ulcerative colitis. A total of 1358 IBD patients were followed from January 1973 to December 1989 . Total community yearly hospital charges for IBD were equal to appendicitis or gallbladder surgery. One in 500 persons in Rochester has IBD. Jews are four times as likely to get Crohn's disease or ulcerative colitis but only $2.8 \%$ of all IBD patients in Rochester were Jewish. As a group, blacks are $50 \%$ less likely than whites to get IBD, yet suburban black IBD rates equated white suburban IBD rates. The incidence of Crohn's disease and ulcerative colitis in people over 60 years of age has risen since 1970 . Complications and secondary comorbidity are frequent in IBD, with thrombophlebitis, pulmonary emboli, sepsis, gallbladder operations and osteoporosis more common in Crohn's disease patients. The number of surgical operations depends on the number of years the patient has had IBD rather than the patient's age. (Pour résumé, voir page 150)

Key Words: Complications of, Crohn's disease, Elderly, Financial impact, Incidence, Inflammatory bowel disease, Jewish/Gentile, Prevalence, Race, Registry, Surgical operations, Ulcerative colitis, Urban/suburban

Isaac Gordon Center for Digestive Diseases and Nutrition, The Genesee Hospital, University of Rochester School of Medicine and Dentistry, Rochester, New York, USA

Dr Segal is now deceased

Correspondence and reprints: Dr James M Stormont, The Isaac Gordon Center for Digestive Diseases, The Genesee Hospital, 224 Alexander Street, Rochester, NY 14607, USA. Telephone (716) 263-6387
THE COLITIS ILEITIS STUDY GROUP 1 of Rochester (CISR), New York, completed a review and analysis of current epidemiological literature and focused on developing a community wide long range analysis of Crohn's disease and ulcerative colitis in Rochester. Clear criteria for diagnosis of definite Crohn's disease and ulcerative colitis, using clinical, $x$-ray and pathology standards, were developed in consultation with the Crohn's and Colitis Foundation of America and the International Organization for Inflammatory Bowel Disease (IBD). From the early 1970s these early diagnostic criteria were encouraged through the CISR and the Rochester Gut Club to establish consistency in diagnosis and adequate hospital chart documentation. After appropriate review and approval by each hospital's human experimentation committee, a community wide registry for Crohn's disease and ulcerative colitis was established in Rochester beginning January 1, 1973.

\section{PATIENTS AND METHODS}

Candidates for admission into the IBD registry included any of the 1.7 million admissions to the seven community hospitals that had IBD listed as 


\section{Analyse à l'échelle communautaire de la maladie intestinale inflammatoire à Rochester, New York, de janvier 1973 à décembre 1989: épidémiologie et analyse clinique détaillée}

RÉSUMÉ: La maladie intestinale inflammatoire est une cible mouvante qui présente des variations interrégionales quant à l'incidence et la prévalence de la maladie de Crohn et de la colite ulcéreuse et une variation importante des taux selon l'année. De vastes études de population, menées sur plusieurs années, peuvent le mieux décrire les tendances de la maladie intestinale inflammatoire et de ses complications, ainsi que l'impact d'un traitement médical et chirurgical. Le Colitis Ileitis Study Group de Rochester, New York, a établi un registre communautaire élargi, pour la maladie de Crohn et la colite ulcéreuse. En tout, 1358 patients atteints de maladie intestinale inflammatoire ont été suivis entre janvier 1973 et décembre 1989. Les frais hospitaliers annuels totaux pour la communauté, en fait de maladie intestinale inflammatoire, équivalaient à ceux de la chirurgie pour l'appendicite ou la vésicule biliaire. Une personne sur 500, à Rochester, présente une maladie intestinale inflammatoire. Les juifs sont quatre fois plus susceptibles d'être atteints de maladie de Crohn ou de colite ulcéreuse, mais seulement $2,8 \%$ de tous les patients atteints de maladie intestinale inflammatoire à Rochester étaient juifs. En tant que groupe, les personnes de race noire sont $50 \%$ moins susceptibles que les personnes de race blanche d'être atteintes de maladie intestinale inflammatoire et pourtant les taux de cette maladie au sein de la population noire des banlieues égalaient ceux de la population blanche des banlieues. L'incidence de la maladie de Crohn et de la colite ulcéreuse chez les gens de plus de 60 ans s'est élevée depuis 1970. Les complications et la présence de maladies concomitantes secondaires sont fréquentes dans la maladie intestinale inflammatoire, avec la thrombophlébite, l'embolie pulmonaire, l'infection, les cholécystectomie et l'ostéoporose, qui sont plus fréquentes chez les patients atteints de maladie de Crohn. Le nombre d'interventions chirurgicales dépend du nombre d'années durant lesquelles le patient a souffert de maladie intestinale inflammatoire plutôt que de son âge.

one of the discharge diagnoses between January 1973 and December 1989, as well as any IBD patients seen for office care by one of the participating physicians in the CISR between January 1973 and December 1989. Computer scan of discharge diagnoses by InfoMed Management Systems identified IBD patients. Registry forms were completed by extracting information from the hospital discharge sheet, surgical and pathology reports. Registry data were entered into an IBM-PC computer, and computerized information was assembled into random access files and manipulated by the statistical software package, PC Statistician (10), and assembled into tables and graphs for analysis. Patients with IBD localized to the rectum only as well as IBD patients not resident in Rochester were excluded from the registry. Information concerning race, ethnicity and residence by census tract was taken from the routine hospital admission interview without other verification.

Morbidity and co-morbidity of IBD were analyzed for all IBD patients hospitalized in Rochester for any reason between January 1980 and December 1986. InfoMed Management Systems scanned 700,000 hospitalizations by DRG (diagnosis related groups) categories and found 1029 hospitalizations for 956 Crohn's disease patients, and 443 total hospitalizations for 630 ulcerative colitis patients. This hospital diagnostic data were organized into tables for analysis for presentation. Concurrent verification of medical and surgical complications of IBD was performed by clinical analysis of all hospital IBD patient charts January 1973 to December 1989.

Analysis of IBD in the elderly (older than 60 years of age) was performed from the IBD registry clinical data that were stratified by age using Stats Plus Statistical Software.

\section{RESULTS}

IBDs are a moving target. New cases of ulcerative colitis and Crohn's disease in Rochester (Figure 1) were counted between January 1973 and December

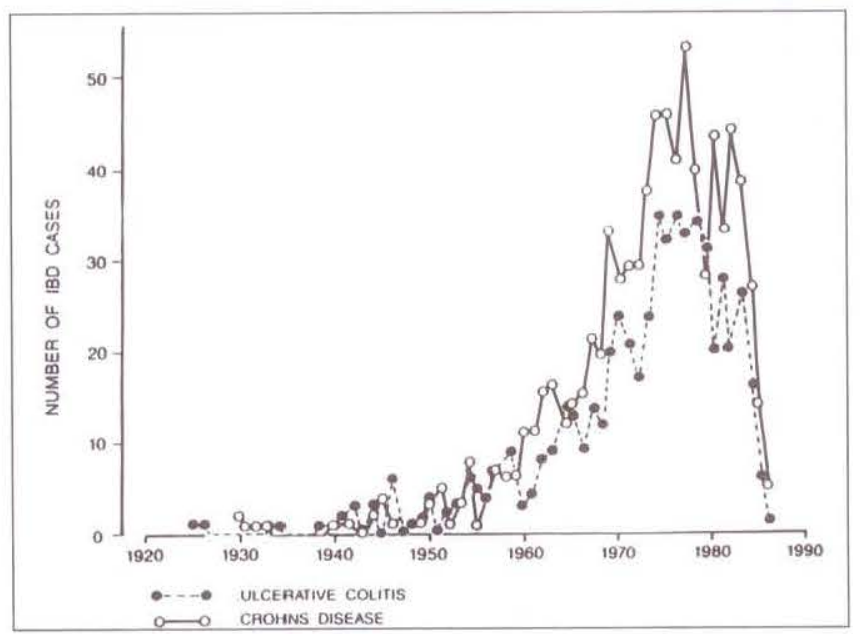

Figure 1) New cases of inflammatory bowel disease (IBD) in Monroe County by year of onset. (Reproduced from reference 1)

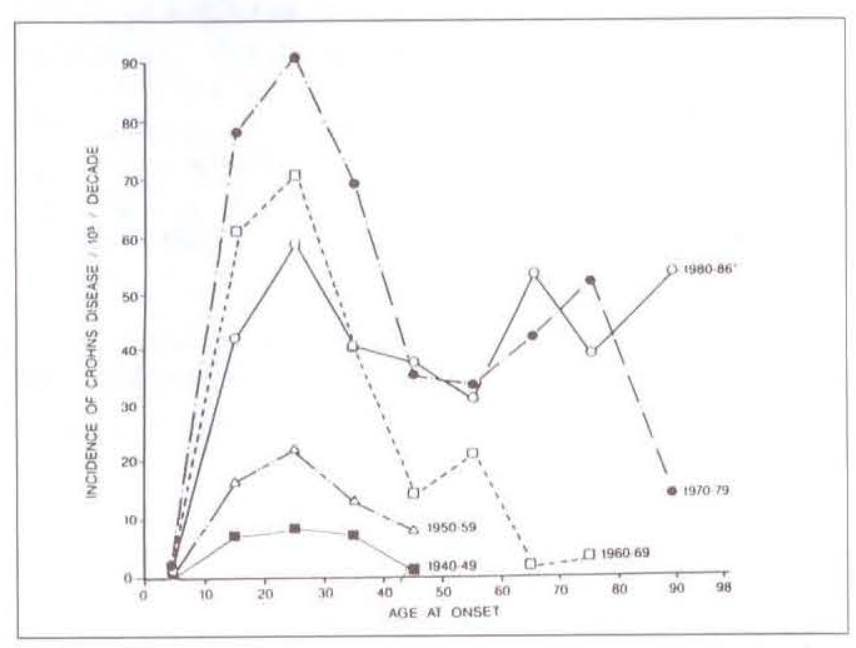

Figure 2) Age-specific incidence rates for Crohn's disease by decade of onset. 1940-86. (Reproduced from reference 1) 
TABLE la

Distribution of IBD by religion ( 852 cases)

\begin{tabular}{lccc}
\hline & Jewish & $\begin{array}{c}\text { Stated } \\
\text { religion }\end{array}$ & $\begin{array}{c}\text { No stated } \\
\text { religion }\end{array}$ \\
\hline Crohn's disease & $9.7 \%$ & $78.0 \%$ & $12.2 \%$ \\
$\begin{array}{l}\text { Ulcerative colitis } \\
\begin{array}{l}\text { Expected rate } \\
\text { based on Jewish }\end{array}\end{array}$ & $12.8 \%$ & $77.9 \%$ & $9.2 \%$ \\
population & $2.8 \%$ & $63.2 \%$ & $34 \%$ \\
\hline
\end{tabular}

Crohn's disease and ulcerative colitis are not predominantly Jewish diseases

1989 , and retrospectively recorded to the 1940s. Access was by community hospital records and patient histories. A rapid rise in new cases of Crohn's disease and a less steep rise in ulcerative colitis was seen January 1973 through 1978, after which the number of new cases of IBD gradually declined through December 1989.

The age-specific incidence rates of Crohn's disease (Figure 2) and ulcerative colitis (Figure 3) were analyzed from 1940 through 1989 and showed that IBD was a disease of adolescents and young adults until 1969. In the 1970s and 1980s there was a rapid rise in the new onset of ulcerative colitis and Crohn's disease in those 60 years and older, so that new onset of ulcerative colitis is as common now in those aged 60 to 75 years as in adolescents. Elderly IBD ranks swell with new onset of Crohn's disease and ulcerative colitis cases as well as adolescent onset of IBD now maturing to old age.

The IBD registry draws from all IBD patients resident in Rochester. From the registry, 852 cases were analyzed for stated ethnicity (Jewish or Gentile, Table la). Jews were four times as likely to get Crohn's disease or ulcerative colitis compared with Gentiles in the community. However, only $10 \%$ of all IBD patients were Jewish. Therefore, in this community Jews are a minority of IBD cases.

A total of 1201 of the IBD registry records were analyzed for race (Table lb). IBD patients were self-identified by race. Blacks were noted to have only one-half of the expected white rate of Crohn's disease and ulcerative colitis. There were no Asian Americans or Hispanics in the IBD registry, although there are small ethnic communities of the same in Rochester.

TABLE 2 suburbs
TABLE Ib

Distribution of IBD by race (1201 cases)

\begin{tabular}{lcccc}
\hline & White & Black & Asian & $\begin{array}{c}\text { American } \\
\text { Indian }\end{array}$ \\
\hline Crohn's disease & $95.1 \%$ & $4.8 \%$ & 0 & 0 \\
Ulcerative colitis & $95.6 \%$ & $4.4 \%$ & 0 & 0 \\
$\begin{array}{l}\text { Expected by } \\
\text { racial popula- } \\
\text { tion distribution* }\end{array}$ & $87.0 \%$ & $10.0 \%$ & 0 & 0 \\
\hline "Rate of IBD in blacks is half that expected & & \\
\hline
\end{tabular}

Stratification of IBD by place of residence in Monroe County - city versus

\begin{tabular}{lcccc}
\hline & \multicolumn{2}{c}{ White } & \multicolumn{2}{c}{ Black } \\
& Cases & Population & Cases & Population \\
\hline City & 357 & 168,102 & 47 & 62,332 \\
Suburbs & 998 & 445,423 & 21 & 6709 \\
City rate & $357 / 168,102=212.37 / 100,000$ & $47 / 62,336=75,40 / 100,000$ \\
Suburban rate & $998 / 445,423=224.06 / 100,000$ & $21 / 8709=241.13 / 100,000$ \\
\hline
\end{tabular}

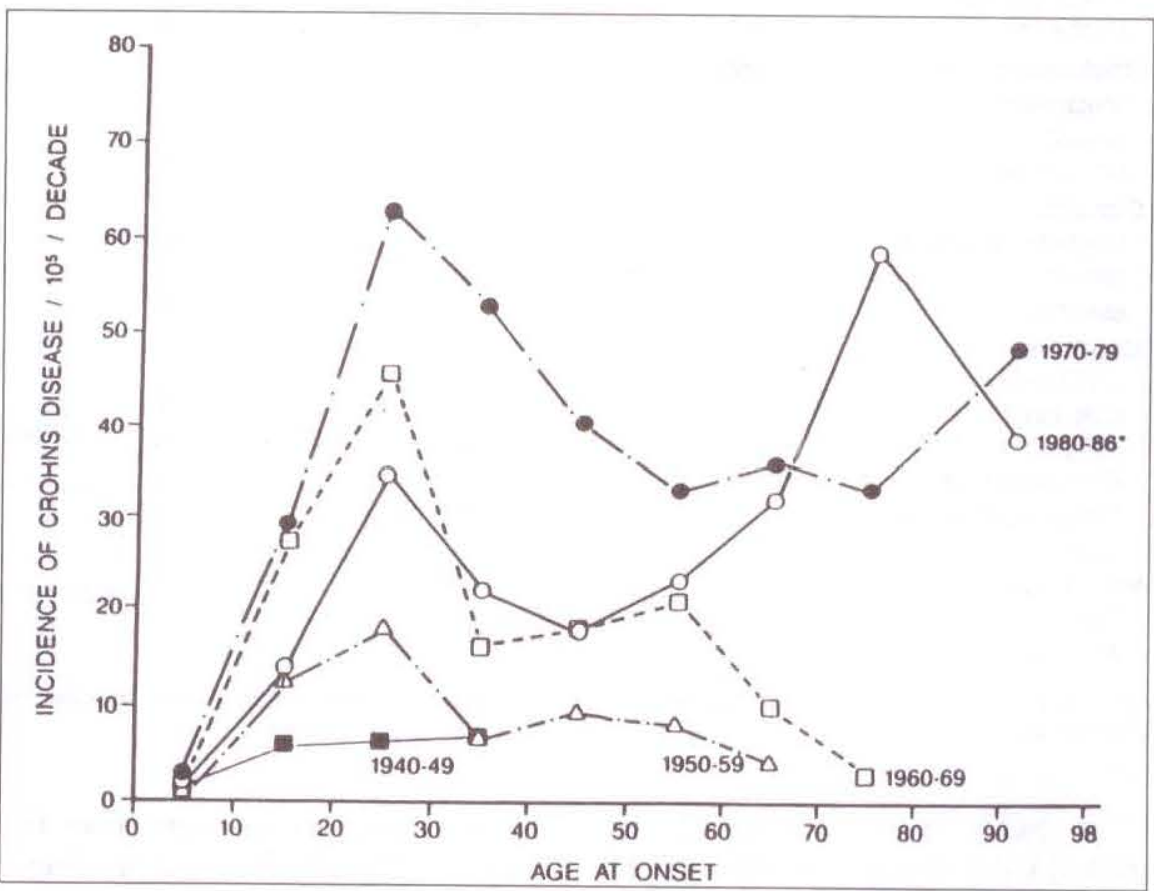

Figure 3) Age-specific incidence rates for ulcerative colitis in Monroe County by decade of onset 1940-86. (Reproduced from reference 1)

The Rochester community is divided into census tracts. Place of residence can be used to define the inner city, more blue collar and poor neighbourhoods, from the suburban more affluent professional residences. Stratification of IBD patients by place of residence and by race is presented in Table 2. The rates of IBD are lower in poorer inner city, more blue collar neighbourhoods than in suburban more affluent white and black neighbourhoods. Moreover, the rates of IBD among affluent suburban blacks was 3.5 times higher than among poorer inner city blacks. Although the total number of suburban blacks with IBD is very small, this contrast raises the question of whether environmental or socioeconomic factors may play a role in triggering IBD. 
TABLE 3

\section{Morbidity of IBD (January 1980 to December 1986)}

\begin{tabular}{|c|c|c|}
\hline Complication & $\begin{array}{l}\text { Crohn's disease } \\
\text { (1029 hospitaliza- } \\
\text { tions/ } 956 \text { patients) }\end{array}$ & $\begin{array}{c}\text { Ulcerative colitis } \\
\text { (443 hospitalizations/ } \\
630 \text { patients) }\end{array}$ \\
\hline \multicolumn{3}{|l|}{ Direct complications of IBD } \\
\hline Bowel obstruction (>69 years) & 182 & 74 \\
\hline Bowel obstruction ( $<70$ years) & 174 & 113 \\
\hline Gl obstruction (> 69 or cc) & 14 & 2 \\
\hline Gl obstruction $(<70)$ & 29 & 1 \\
\hline Appendectomy (< 70 or cc) & 9 & 1 \\
\hline Appendectomy $(>69)$ & 3 & 0 \\
\hline Malnutrition & 11 & 8 \\
\hline Cellulitis & 4 & 1 \\
\hline \multicolumn{3}{|l|}{ Secondary complications of IBD } \\
\hline Deep venous thrombophlebitis & 3 & 1 \\
\hline Pulmonary emboli & 2 & 0 \\
\hline Gallbladder operation & 7 & 0 \\
\hline Sepsis & 5 & 0 \\
\hline Ureteral stones $($ age $<70)$ & 4 & 4 \\
\hline Ureteral stones (age $>69$ or $\mathrm{cc}$ ) & 3 & 0 \\
\hline \multicolumn{3}{|l|}{ Complications of therapy/medication } \\
\hline Peptic ulcer & 3 & 1 \\
\hline Fractured hip/femur $($ age $<70)$ & 3 & 1 \\
\hline Fractured hip/femur (age > 69 or cc) & 2 & 1 \\
\hline Fractured hip/pelvis & 2 & 0 \\
\hline Diabetes & 0 & 1 \\
\hline \multicolumn{3}{|l|}{ Obstetric/gynecological factors } \\
\hline Vaginal delivery & 2 & 5 \\
\hline Cesarean section & 3 & 0 \\
\hline Uterus/adnexal operation & 3 & 1 \\
\hline \multicolumn{3}{|l|}{ Cancer } \\
\hline Leukemia/lymphoma & 2 & 0 \\
\hline Breast & 0 & 1 \\
\hline Lung & 3 & 0 \\
\hline \multicolumn{3}{|l|}{ Cardiovascular } \\
\hline CVD and myocardial infarction & 1 & 3 \\
\hline CHF and shock & 1 & 3 \\
\hline Angina & 1 & 0 \\
\hline Coronary artery bypass graft & 2 & 1 \\
\hline $\begin{array}{l}\text { Major vascular operation } \\
\text { (age > } 69 \text { or cc) }\end{array}$ & 3 & 1 \\
\hline \multicolumn{3}{|l|}{ Psychiatric } \\
\hline Psychosis & 7 & 1 \\
\hline Alcohol/drug abuse & 1 & 1 \\
\hline
\end{tabular}

CC Complicating condition: CHF Congestive heart failure; CVD Cardiovascular disease: $G$ Gastrointestinal

Morbidity of IBD (Table 3) was studied for the entire community from January 1980 to December 1986. A total of 700,000 hospitalizations was analyzed and revealed 1029 hospitalizations of all types for 956 Crohn's disease patients, and 443 hospitalizations of all types for 630 ulcerative colitis patients. Only $41 \%$ of Crohn's disease hospitalizations and $45 \%$ of ulcerative colitis hospitalizations were for direct care of IBD and immediate IBD surgery.

Analysis of patients hospitalized for 'indirect' complications revealed that events such as venous thrombosis, gallbladder surgery, sepsis, fractured hips and cesarean sections were more frequent in Crohn's disease than ulcerative colitis patients.

To determine the relationship between age and IBD, the IBD registry information was stratified according to the number of operations related to age of the patient, and the number of years of IBD. It was found that the number of operations conducted on Crohn's disease patients correlated with the number of years they had suffered from IBD. This was true both for the under 60 and older age groups. Similar stratification of ulcerative colitis patients by years of IBD also held true for those under and
TABLE 4

Number of surgical procedures by disease duration in years

\begin{tabular}{|c|c|c|}
\hline $\begin{array}{l}\text { Disease } \\
\text { duration }\end{array}$ & $\begin{array}{c}\text { Geriatric } \\
(\text { age } \geq 65 \text { ) }\end{array}$ & $\begin{array}{c}\text { Nongeriatric } \\
\text { (age < 65) }\end{array}$ \\
\hline \multicolumn{3}{|c|}{ Crohn's disease } \\
\hline $0-9$ & $24(n=34)$ & $173(n=287)$ \\
\hline $10-19$ & $29(n=27)$ & $326(n=250)$ \\
\hline $20-29$ & $31(n=17)$ & $125(n=56)$ \\
\hline $30-39$ & $22(n=10)$ & $48(n=24)$ \\
\hline $40-49$ & $4(n=2)$ & $13(n=3)$ \\
\hline$\geq 50$ & $13(n=4)$ & $0(n=0)$ \\
\hline Total & $123(n=94)$ & $685(n=620)$ \\
\hline \multicolumn{3}{|c|}{ Ulcerative colitis } \\
\hline $0-9$ & $10(n=29)$ & $66(n=161)$ \\
\hline $10-19$ & $13(n=27)$ & $71(n=159)$ \\
\hline $20-29$ & $7(n=14)$ & $36(n=51)$ \\
\hline $30-39$ & $8(n=10)$ & $20(n=15)$ \\
\hline $40-49$ & $0(n=1)$ & $11(n=3)$ \\
\hline$\geq 50$ & $5(n=2)$ & $0(n=0)$ \\
\hline Total & $43(n=83)$ & $204(n=389)$ \\
\hline
\end{tabular}

over 60 years old (Table 4). Thus, age seems to be less of a determinant for surgery than the duration of IBD.

\section{DISCUSSION}

The CISR studies are unique because of the large size of the community investigated $(600,000$ persons, 1358 IBD patients) and the duration of follow-up (up to 17 years and continuing). The access to hospital managemen figures for an entire American com munity for seven hospitals is also unique. These studies are comprehensive and complete as of December 1989.

The IBD registry is limited by excluding proctitis and some of the milder IBD patients seen only in the office. The incidence figures for Crohn's disease and ulcerative colitis before 1970 may be limited by physician IBD awareness as well as problems of definition of Crohn's colitis versus ulcerative colitis.

Clear clinical definitions of Crohn's disease and ulcerative colitis with $\mathrm{x}$-ray and pathology verification, as well as clear definitions of IBD causing complications, and IBD and related processes causing death, focus and verify the clinical conclusions.

The fiscal and use data are accurate for 1980-81, but do not translate to other communities or other times.

The data linking race and ethnicity 

APPENDIX A
Registry form
PART ONE: Patient details
1. Name
2. Date of birth
3. Diagnosis
4. Place of birth (state)
5. If 4 is New York what county? Present address
6. Town/Village/City
7. County
8. Census tract
9. Sex
10. Race
11. Ethnic group
12. Occupation

\section{PART TWO: Physician ID and hospitalization}
13. Attending MD
14. Attending surgeon
15. Attending gastroenterologist
16. Date of last hospitalization for IBD
17. Name of hospital
18. Hospital chart number
19. Primary care physician

\section{PART THREE: Disease verification}

20. Reason patient visited physician which led to diagnosis of Crohn's disease (subjective onset)

21. Date of onset (symptoms)

22. Definitive pathological diagnosis (objective onset)

23. Date

24. Location in bowel

25. Complication(s) (most recent)

27. Total number of surgical procedures for IBD

130)

\section{APPENDIX B \\ Questions}

IBD is a moving target

- There has been rapid rise in new cases of $\mathrm{UC}$ but not $C D$ in the past 20 years

- There has been a rapid rise in new cases of $C D$ and ulcerative colitis in the elderly (older than 60 years)*

- IBD is equal in rural, inner city and suburban populations

\section{Who gets IBD?}

- Mostly disease of Jews

- Equal risk Jews and Gentile

- Equal risk black and white

- None of the above

Complications of IBD

- $C D$ versus UC - Thrombophlebitis. pulmonary emboli, gallbladder operation, cancer of the lung and osteoporosis more likely in UC

- IBD complications and number of operations relate to years of IBD not age of patient*

- Referral centre data are accurate in establishing rate of medical complications and surgical operations in IBD patients

- Surgical complication and mortality are extremely high in elderly patients who have IBD surgery

Analysis of causes of death in IBD (January 1973 to December 1989)

- Most IBD patients die from IBD

- Elderly IBD patients are more likely to die from IBD

- Colorectal cancer deaths in UC patients are more common if older than 70 years

- Highest risk of death from UC (excluding colon cancer) is in first two years*

-Denotes true statement. CD Crohn's disease: UC Ulcerative colitis

to IBD suffered by accepting the patient's opinion "I am black", etc, without any other verification. Genetic and genealogical data were not available.

The morbidity data for IBD from January 1980 to December 1986 is more credible by being a complete computer scan of all 700,000 community hospitalizations. The morbidity data are limited by the accuracy and completeness of the discharge file diag. nosis list. The co-morbidity was crosschecked and found accurate within DRG nomenclature, in part, by the IBD registry surgical data obtained by detailed analysis of all hospital IBD 
charts from January 1973 to December 1989. Details of rates of ureteral stones, osteoporosis, bone fractures and angina pectoris can best be established by prospective studies verifying each case diagnosis.

Early studies of IBD complications and deaths due to IBD were done in an era of less sophisticated antibiotics and surgery, and with modem nutritional support. The current data on rates for IBD surgery and complications suggest that the physiology of ageing is less important in the years of active IBD. The fact that fewer IBD patients die from the disease in spite of the cumulative

ACKNOWLEDGEMENTS: This research was supported in part by The Anthony Comparato IBD Research Fund at The Genesee Hospital, The McCurdy Fund at The Genesee Hospital and the Crohn's Colitis Foundation of America. Special thanks to $\mathrm{Mr}$ James Crommiller for statistical analysis, Mrs Noreen Naud for secretarial editing assistance and $\mathrm{Mr}$ Thomas Domhoff for data compilation.

\section{REFERENCES}

1. Stowe SP, Redmond S, Stormont JM, et al. An epidemiologic study of inflammatory bowel disease in Rochester, NY - hospital incidence. Gastroenterology 1990;98:104-10.

2. Monk M, Mendeloff AI. An epidemiologic study of ulcerative colitis and regional enteritis among numbers of IBD patients is a tribute to earlier diagnosis, and better medical and surgical therapy.

Regional differences may abound in the incidence and prevalence of Crohn's disease and ulcerative colitis, rates of IBD complications, and types and frequency of deaths due to IBD. We have attempted to make the best detailed clinical description of IBD from our living laboratory of IBD in Rochester, New York.

\section{CONCLUSIONS}

Crohn's disease and ulcerative colitis are diseases of major impact in

adults in Baltimore. Gastroenterology 1967;53:198-210.

3. Garland CF, Lillienfeld AM, Mendeloff AI, Markowitz JA, Terrell $\mathrm{KD}$, Garland FC. Incidence of ulcerative colitis and Crohn's disease in fifteen ares of the United States. Gastroenterology 1981;81:1115-24.

4. Evans JG, Acgson ED. An epidemiological study of ulcerative colitis and regional enteritis in the Oxford area. Gut 1965;6:311-24.

5. Kyle J. An epidemiologic study of Crohn's disease in Northeast Scotland. Gastroenterology 1971;61:826-33.

6. Binder B, Both H, Hansen BK, Hendrickson C, Kriner S, Torp-Petersen K. Incidence and prevalence of ulcerative colitis and Crohn's disease in the County of Copenhagen 1962-1978. urban North American cities, affecting one in 500 persons and having yearly hospital charges equal to appendicitis or gallblaader surgery. Jews are four times more likely to get Crohn's disease and ulcerative colitis than Gentiles, whereas blacks are half as likely as whites to get IBD. The incidence and prevalence of IBD has risen in the elderly (older than 60 years) since 1970. Complications of IBD are frequent and occur more often in Crohn's disease than ulcerative colitis patients. The number of surgical operations depend on the duration of IBD rather than the patient's age.

Gastroenterology 1982;83:563-8.

7. Mayberry J, Rhodes J, Hughes LE. Incidence of Crohn's disease in Cardiff between 1934-1977. Gut 1979;20:602-8.

8. Shivana DA, Pena AS, Nap M, et al. Epidemiology of Crohn's disease in Regio Lieden, Netherlands - a population study. Gastroenterology 1987;93:966-74

9. Stowe SP, Segal HL, Redmond SR, Stormont JM, Chey WY, Shah AN. Fiscal and hospital utilization impact of IBD in Rochester, NY community hospitals. Presented at the Second International Symposium on IBD, Jerusalem, Israel, September 1985.

10. Madigan SP. PC Statistician Software, a statistical report program for the IBM-PC. Human Systems Dynamics, Northridge, California, 1983. 


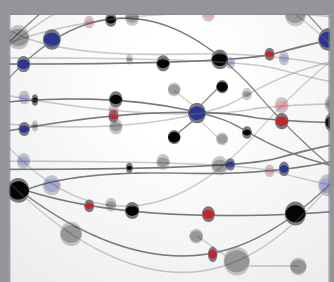

The Scientific World Journal
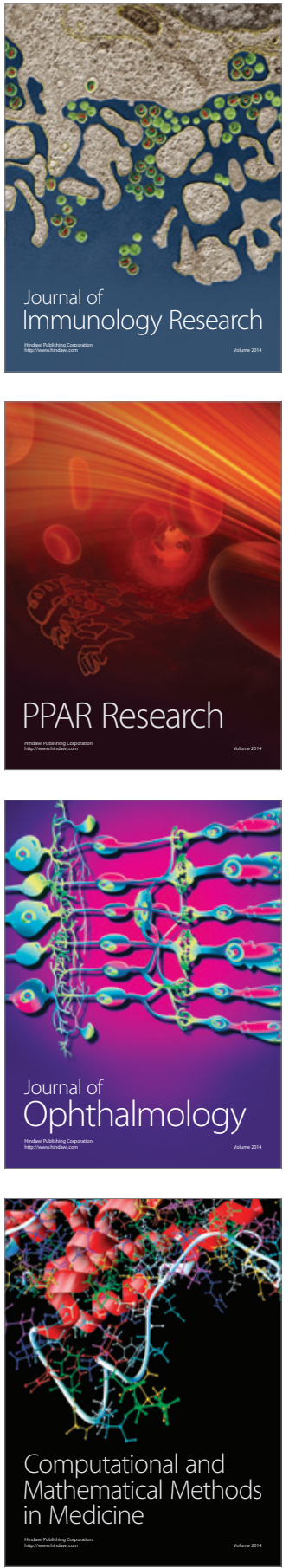

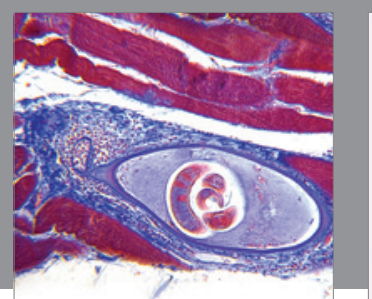

Gastroenterology Research and Practice

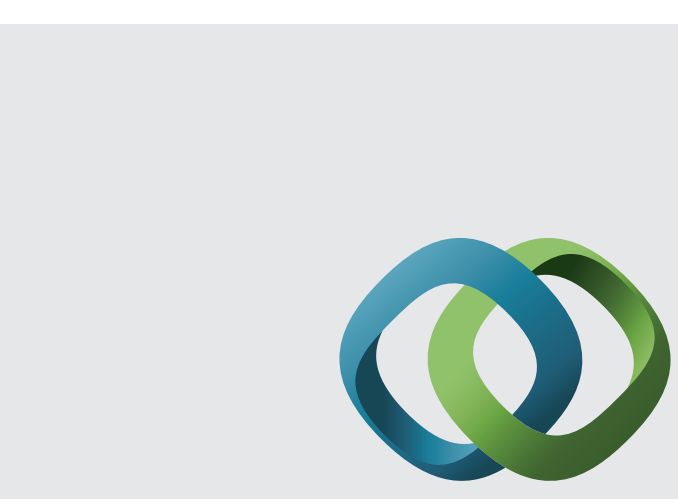

\section{Hindawi}

Submit your manuscripts at

http://www.hindawi.com
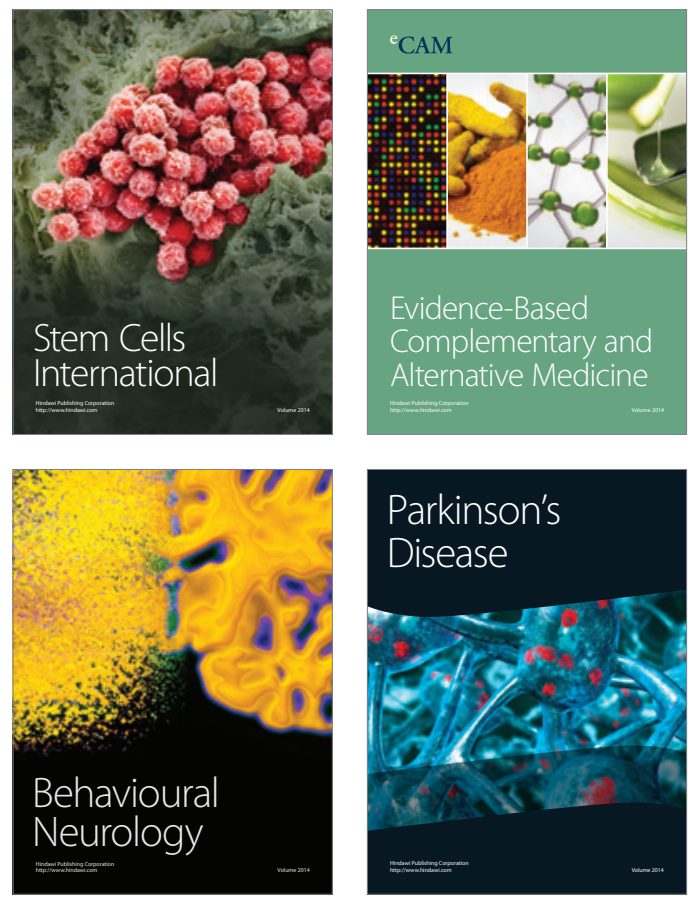
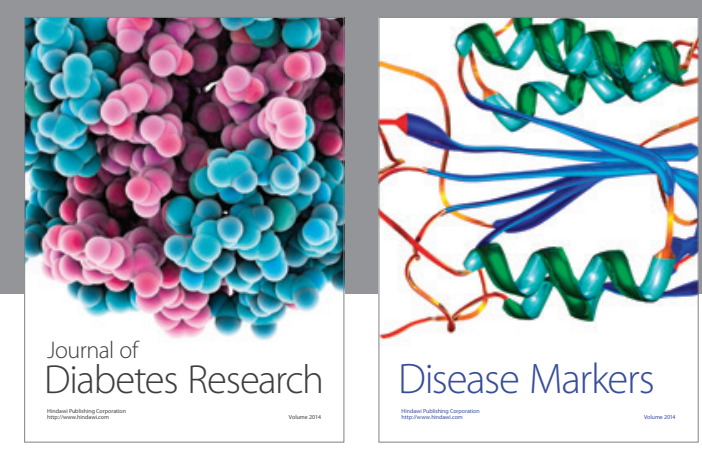

Disease Markers
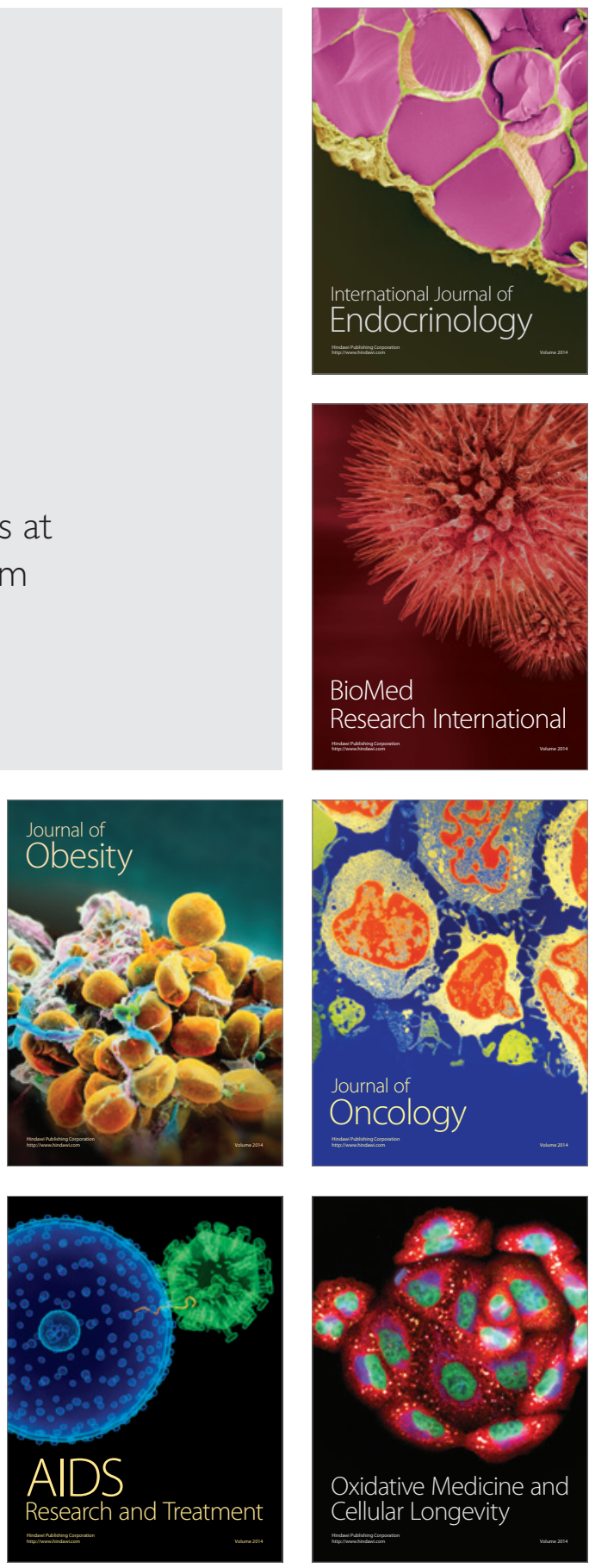